\title{
David Oliver: Allow nurses to use their professional judgment
}

\author{
David Oliver consultant in geriatrics and general internal medicine
}

Berkshire

In January the Nursing and Midwifery Council (NMC) suspended a nurse's registration for 12 months because she'd decided not to commence cardiopulmonary resuscitation (CPR) in an elderly, dying care home resident. ${ }^{12}$

An earlier panel had heard evidence that the resident was "waxy, yellow and almost cold" when the nurse decided not to initiate CPR or call paramedics. ${ }^{3}$ The NMC concluded that the nursing profession had been brought into disrepute, the nurse's fitness to practise impaired, and her patient put at risk of harm. The nurse had the option to appeal the decision.

The nurse did not attend this January's hearing and had "disengaged from the proceedings, retired from nursing and moved to the USA." 2 This case sets a worrying precedent by questioning the professional skill and autonomy of registered nurses. They don't rely on delegated authority from doctors but are independent practitioners who make assessments and judgments every day.

Acute hospitals will have a crash team and access to rapid critical care outreach support and medical opinions. Nurses who see patients in their own homes or are working in a long term care facility can call for an ambulance or phone a GP-but they're the onsite first responders and must exercise clinical judgment.

People who have entered UK residential care or nursing homes are generally older, with multiple long term conditions and severe frailty, often with dementia and generally with significant age related impairment and disability. They're mostly entering the last year or two of life, and if they don't die in these homes they will do so having been conveyed to hospital in an ambulance, often for want of advance care planning and therapeutic or palliative care support within the home. End of life care is, in effect, "core business" for them. And if we want to help more residents avoid admission-especially when dying - then unhelpful action from regulators such as the NMC or the Care Quality Commission won't help nurses do the right thing for residents.

Even when CPR is attempted, the 30 day survival rate from cardiac resuscitation in nursing home residents is less than $2 \%{ }^{4}$
Given this, shouldn't we be praising, not blaming, nurses for using professional situational judgment about a resident they're caring for and can see is close to death? Failure to commence CPR is labelled as a "risk of harm." But what about the risk of harm from chest compressions, shocks, futile and distressing ambulance conveyance, or hypoxic brain damage - not to mention the human indignity of someone undergoing CPR when already so vulnerable?

In 2017 the NMC made a public statement "regarding decisions relating to cardiopulmonary resuscitation" 5 and citing joint guidance from 2016 on not attempting CPR, issued by the Royal College of Nursing, BMA, and Resuscitation Council. ${ }^{6}$ The NMC said that "an initial presumption [by the nurse] in favour of CPR ... does not mean indiscriminate application of CPR that is of no benefit and not in the person's best interests"; “. . . there will be cases where healthcare professionals discover patients with features of irreversible death"; and, "in such circumstances, any healthcare professional who makes a carefully considered decision not to start CPR should be supported by their senior colleagues, employers and professional bodies." 5

The NMC's chief executive, Andrea Sutcliffe, wrote a detailed blog ${ }^{7}$ in response to public criticism of the 2020 ruling, including some in the Nursing Standard. She explained in detail the facts of the case and the rationale of the decision. This included an apparent failure even to consider CPR-with the nurse saying in a phone call that "we are a nursing home and don't do CPR here,"-as well as a failure to adhere to the care home's own policies, document the rationale for her decision, or demonstrate any critical thinking.

Even if we accept the NMC's defence, surely the nurse's employers had a responsibility regarding her knowledge of processes. More to the point, the effect will inevitably be to damage nurses' confidence in the NMC and make it more likely that dead or dying residents are subjected to pointless CPR, or conveyance to hospital, that is not in their interests.

\section{Competing interests: See bmj.com/about-bmj/freelance-contributors}


Provenance and peer review: Commissioned; not externally peer reviewed.

1 Jones-Berry S. NMC suspends nurse for failing to give CPR to care home resident. Nurs Stand 2020 Jan 21. https://rcni.com/nursing-standard/newsroom/news/nmc-suspendsnurse-failing-to-give-cpr-to-care-home-resident-157026.

2 Nursing and Midwifery Council Fitness to Practise Committee. 6-9 Jan 2020. https://www. nmc.org.uk/globalassets/sitedocuments/ttpoutcomes/2020/january-2020/reasons-nasiriftpcsh-67721-20200109.pdf

3 McCartney M. Margaret McCartney: Nurses must be allowed to exercise professional judgment. BMJ 2017;356:j1548. 10.1136/bmj.j1548 28351839

4 Pape M, Rajan S, Hansen SM, etal . Survival after out-of-hospital cardiac arrest in nursing homes-a nationwide study. Resuscitation 2018;125:90-8. 10.1016/j.resuscitation.2018.02.004. https://www.ncbi.nlm.nih.gov/pubmed/ 29425977. 29425977

5 Nursing and Midwifery Council. Joint NMC/RCN statement regarding decisions relating to cardiopulmonary resuscitation. 21 Jun 2017. https://www.nmc.org.uk/news/news-andupdates/joint-nmc-rcn-statement-decisions-cpr.

6 Resuscitation Council. Do Not Attempt CPR—Decisions relating to cardiopulmonary resuscitation (3rd ed, 1st rev). Jun 2017. https://www.resus.org.uk/dnacpr/decisionsrelating-to-cpr/.

7 Sutcliffe A. Blog: Reflections on recent CPR fitness to practise case. Nursing and Midwifery Council. 27 Jan 2020. https://www.nmc.org.uk/news/news-and-updates/reflections-onrecent-cpr-fitness-to-practise-case/,

Published by the BMJ Publishing Group Limited. For permission to use (where not already granted under a licence) please go to http://group.bmj.com/group/rights-licensing/ permissions 